\title{
ÍNDICE DE VULNERABILIDADE DAS ÁGUAS SUBTERRÂNEAS NO MUNICÍPIO DE ROSÁRIO DO SUL, RIO GRANDE DO SUL
}

\author{
Tiago Ertel ${ }^{1}$, Carlos Alberto Löbler ${ }^{2}$, José Luiz Silverio da Silva ${ }^{3}$ \\ ${ }^{1}$ Universidade Federal de Santa Maria - UFSM: tiago ertel@hotmail.com \\ 2 Universidade Federal de Santa Maria - UFSM: carloslobler@gmail.com \\ ${ }^{3}$ Universidade Federal de Santa Maria - UFSM: silverioufsm@gmail.com
}

\section{RESUMO}

Esta pesquisa faz parte do Projeto Integração dos instrumentos de Outorga, Enquadramento e Cobrança para a Gestão das águas subterrâneas. Seu objetivo foi estudar a vulnerabilidade à contaminação das águas subterrâneas do município de Rosário do Sul, no Estado do Rio Grande do Sul, na borda da Bacia do Paraná e parte da zona de afloramentos (ZA) do Sistema Aquífero Guarani (SAG). O qual constitui um aquífero poroso, livre, intergranular, pertencente à Formação Pirambóia. Buscou-se estabelecer seus índices de vulnerabilidade natural à contaminação, utilizando-se o método (GOD) adaptado para as condições brasileiras. Elaborou-se um banco de dados hidrogeológicos contendo informações de 35 captações que continham todas as informações necessárias à aplicação do método (Grau de confinamento, Meio Aquífero e Profundidade do nível da água). Verificou-se a classe predominante na área do estudo (ZA) do SAG foi a Alta (com 40,00\%), seguida de vulnerabilidade Média (com 28,57\%), Baixa (14,29\%), Extrema (14,29\%) e Insignificante (2,85\%).

Palavras-chave: Vulnerabilidade, SAG, GOD, Aquífero.

\section{ABSTRACT}

This research is part of integration award of instruments, and collection guidelines for the management of groundwater Project. The objective of this work was to study the groundwater vulnerability of the Rosario do Sul city, in Rio Grande do Sul state, southern Brazil on the edge of the Paraná Basin. It is part of the outcrops zone (ZA) Guarani Aquifer System (GAS). This aquifer is porous, unconfined, intergranular, unconfined belonging to Pirambóia Formation. Was estimated the aquifer pollution vulnerability index map using the GOD methodology adapted to Brazilian conditions. Were developed a database of 35 tubular wells associated with the hydrogeological characteristics of the overlying vadose zone necessary to use. Was considered groundwater hydraulic confinement, overlying strata and the depth to groundwater table. The range of the vulnerability Index was High (40.00\%), followed Moderate (28.57\%), Low (14.29\%), Extreme $(14.29 \%)$ and Negligible (2.85\%) from the total studied area.

Key-words: vulnerability, GAS, GOD, aquifer. 
Rev. Elet. em Gestão, Educação e Tecnologia Ambiental (e-ISSN: 2236-1170)

\section{INTRODUÇÃO}

No Brasil, a Constituição Federal (1988) estabelece em seu Art. 26 que a titularidade das águas superficiais e subterrâneas é competência dos estados.

O Decreto Estadual 42.047/2002 estabelece que a proteção das águas subterrâneas e dos aquíferos no Estado do Rio Grande do Sul compete ao Departamento de Recursos Hídricos (DRH) da Secretaria do Meio Ambiente.

Já o Código Estadual do Meio Ambiente, em seu Art. 134, estabelece que a escolha da localização de empreendimentos de qualquer natureza deve considerar prioritariamente a vulnerabilidade dos lençóis de água.

A Lei Federal № 9.433/1997, Art. 1ำ, Inciso IV, estabelece que a bacia hidrográfica é a unidade de gestão.

No Estado do Rio Grande do Sul, a SEMA (2005) considerou três Regiões Hidrográficas (GGuaiba); (L-Litorânea) e (U-Uruguai). O município de Rosário do Sul juntamente com os municípios de Santana do Livramento, Cacequi, Dom Pedrito, Lavras do Sul e São Gabriel formam a Bacia Hidrográfica do Rio Santa Maria/BHRSM (U-70) pertencente a Região Hidrográfica do Uruguai (SEMA, 2005).

A área em estudo faz parte da borda da Bacia Sedimentar do Paraná que tem continuidade no Uruguai, na Argentina e no Paraguai. Formando um aquífero transfronteiriço.

A sequência de rochas sedimentares clásticas com cerca de 130 a 250 milhões de anos constitui as camadas denominadas de Sistema Aquífero Guarani/SAG. O SAG ocorre em parte de oito estados brasileiros (correspondendo a $71 \%$ do total): Goiás $\left(55.000 \mathrm{~km}^{2}\right.$ ), Mato Grosso $\left(26.400 \mathrm{~km}^{2}\right)$, Mato Grosso do Sul $\left(213.200 \mathrm{~km}^{2}\right)$, Minas Gerais $\left(51.300 \mathrm{~km}^{2}\right)$, Paraná $(131.300$ $\left.\mathrm{km}^{2}\right)$, Rio Grande do Sul $\left(157.600 \mathrm{~km}^{2}\right)$, Santa Catarina $\left(49.200 \mathrm{~km}^{2}\right)$, São Paulo $\left(155.800 \mathrm{~km}^{2}\right)$. Este é transfronteiriço com o Uruguai $\left(45.000 \mathrm{~km}^{2}\right)$, Argentina $\left(225.500 \mathrm{~km}^{2}\right)$ e Paraguai $\left(71.700 \mathrm{~km}^{2}\right)$ (OEA/SAP, 2009).

Assim a BHRSM, com uma área de 15.797,300 km² (ASUB/UFCG/UFAL/UFSM, 2009) é transfronteiriça tendo continuidade com o Uruguai, onde ocorrem os arenitos da Formação Tacuarembó. Desta maneira os arenitos pertencentes a (ZA), ocorrem em uma escala superior ao da BHRSM, correspondendo à cerca de $36 \%$ desta bacia (DESCOVI FILHO, 2009).

O município de Rosário do Sul pertence a (ZA) do SAG (OEA/SAP, 2009) onde ocorrem rochas sedimentares arenosas a silto-argilosas pertencentes a Formação Rosário do Sul/Pirambóia (CPRM, 2008). Ainda ocorrem afloramentos penetrados por cinco poços tubulares em folhelhos da Formação Irati (pré-SAG) (CPRM/SIAGAS, 2012). Esta localmente fornece água salobra (rica em sais dissolvidos) e não potáveis (Portaria MS 2914/2011).

Desta forma devido às dimensões elevadas da BHRSM este estudo piloto de vulnerabilidade do aquífero à contaminação foi executado na escala de município. Estudos de vulnerabilidade na bacia foram executados por Pavão (2004), Descovi Filho (2009), Descovi Filho et al. (2010), Dambrós et al. (2011) e Silvério da Silva; Dambrós (2012).

$\mathrm{Na}$ área urbana de Rosário do Sul foram cadastrados pontos potenciais de contaminação que foram: sete postos de combustíveis (sendo um pertencente a zona rural), dois cemitérios, um ponto de lavagem de veículos automotores e um ponto de aviação agrícola (lavagem de agrotóxicos), ilustrado no cartograma de vulnerabilidade.

A Resolução nำ15, Art. 1을 do Conselho Nacional de Recursos Hídricos, define água subterrânea como água que ocorre naturalmente ou artificialmente no subsolo. 
Segundo Foster et al. (2006) "a maior parte da água subterrânea se origina a partir do excesso de chuva que se infiltra na superfície do solo."

Até a década de 70, acreditava-se que as águas subterrâneas estavam naturalmente protegidas da contaminação pelas camadas de solo e rochas. Entretanto, a partir de então, passaram a ser detectados traços da presença de contaminantes em águas subterrâneas, e diversos estudos têm sido conduzidos no sentido de avaliar a sua seguridade. Atualmente sabe-se que vários fatores podem comprometer sua qualidade. (SILVA; ARAÚJO, 2003).

Ainda segundo os autores "as atividades que se desenvolvem na superfície podem ameaçar a qualidade da água". Com isso torna-se importante conhecer os aspectos intrínsecos da geologia do local onde esta instalado o empreendimento potencialmente poluidor, observando-se a capacidade de infiltração proporcionada pelos materiais que compõem os solos e/ou áreas de afloramento de rocha sedimentares. Quanto maior a capacidade de infiltração da água, maior será o perigo de contaminação das águas subterrâneas. Assim, terrenos de composição arenosa e porosa, apresentam uma maior relação entre porosidade e permeabilidade, sendo mais suscetíveis ao fluxo e espalhamento de plumas contaminantes. Já os terrenos argilosos, que são de baixíssima permeabilidade, dificultam o fluxo de fluidos, sejam eles contaminantes ou não. Estes formam os aquicludes (não aquíferos) (MACIEL FILHO; NUMMER 2011). Porém deve-se ainda informar que solos argilosos podem apresentar alta porosidade (em torno de 50\%), enquanto os arenitos (em torno de 25\%) Heath (1983). Estes fatores intrínsecos do meio são os principais a serem considerados nos métodos de avaliação da vulnerabilidade do aquífero à contaminação.

No município de Rosário do Sul, ainda nota-se a presença de alguns riscos potenciais, tais como:

1. Esgotos parcialmente coletados e não tratados;

2. Poços de combustíveis que contam com reservatórios subterrâneos, podendo alterar a qualidade da água com contaminantes do grupo dos hidrocarbonetos (BTEX). Para isso considera-se que os constituintes da gasolina, em fase líquida, se dissolvem prontamente em água e incluam os oxigenados (etanol e metanol), fenóis e hidrocarbonetos aromáticos simples (benzeno, tolueno, e xilenos) (Guiguer, 2000).

Para a regulamentação deste tipo de empreendimento potencialmente contaminante das águas subterrâneas, existe a Resolução $n^{\circ}$ 273/2000 do CONAMA (Conselho Nacional do Meio Ambiente) que estabelece, as diretrizes para o licenciamento ambiental de postos de combustíveis e serviços, e dispõe sobre a prevenção e controle da poluição;

3. Os cemitérios, regulamentados nas resoluções Conama no 335/2003 e n 368/2006 do CONAMA;

4. Lavagens de veículos automotores;

5. Usos da aviação agrícola e lavagens de reservatórios;

6. "Lixões" e aterros sanitários.

O método GOD, Foster et al. (2006), foi desenvolvido para avaliar as condições naturais de atenuação de contaminantes e é amplamente utilizado para as condições brasileiras, pois seu uso é simplificado e necessita de apenas três parâmetros. Sabe-se da existência de vários outros métodos de avaliação da vulnerabilidade tais como Drastic, Aller et al. (1987) e Aquifer Vulnerability Index (AVI) Stempvoort et al. (1992), Índice de susceptibilidade (I/S) Ribeiro (2005). 


\section{CARACTERIZAÇÃO DA ÁREA DE ESTUDO}

O município de Rosário do Sul localiza-se no Sudoeste do Estado do Rio Grande do Sul, sob as coordenadas geográficas -30 -15' latitude sul e 555' longitude Oeste Greenwich, situado a 355 km da capital do estado. A população do município, segundo o CENSO 2010 do Instituto Brasileiro de Geografia e Estatística (IBGE), era de 39.707 habitantes.

O município pertence à Microrregião Campanha Central e à Mesorregião Sudoeste RioGrandense, na Bacia Hidrográfica do Rio Santa Maria (U-70) (SEMA, 2005). A área municipal é de 4.369,669 km², representando 1,6251\% Do estado do Rio Grande do Sul. A Figura 1 mostra a localização da sede urbana e do Município de Rosário do Sul no Estado do Rio Grande do Sul.

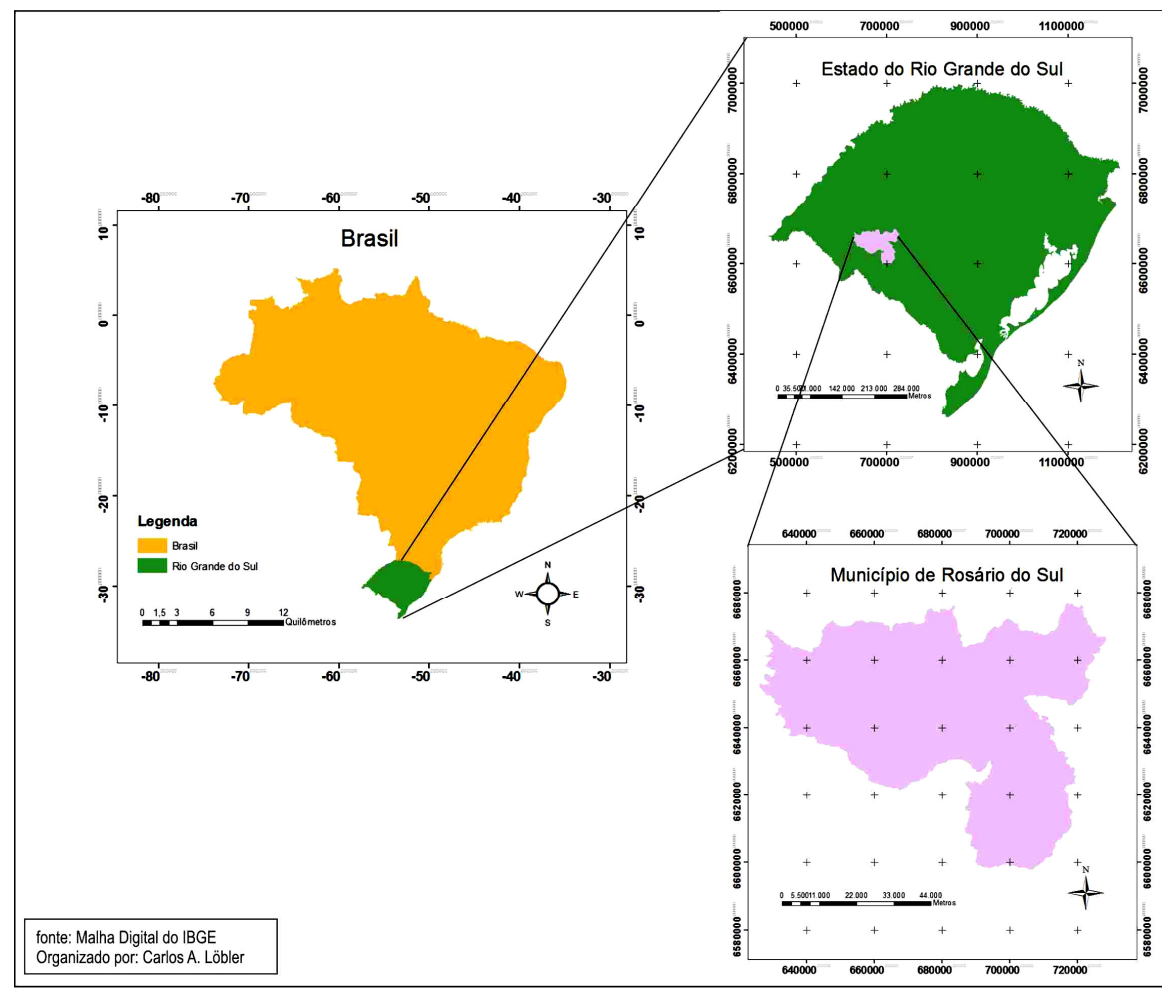

Figura 1. Localização da sede urbana e do Município de Rosário do Sul no Estado do Rio Grande do Sul.

\section{METODOLOGIA}

O presente trabalho teve início com a formatação de um banco de dados de captações cadastradas no município (buscados no sítio da web do CPRM, SIAGAS). Dos 101 poços cadastrados, 35 foram selecionados para a pesquisa por possuírem todas as informações necessárias para análise através do método GOD.

Foster et al. (2006) caracterizam a vulnerabilidade do aquífero à contaminação:

1. Tipo de ocorrência da água subterrânea (G), onde os valores são obtidos em um intervalo de 0 a 1.

2. Classificação dos estratos acima da zona saturada do aquífero em termos do grau de consolidação e caráter litológico (O), esta propriedade conduzirá a um segundo ponto na escala que varia 0,3 a 1,0 . 
3. Determinação da profundidade do nível freático (D), que definirá o terceiro ponto, no intervalo de 0,4 a 1,0. Quanto mais profundo o nível da água, menor a nota. Sendo que será menor o risco de contaminação pois é mais difícil o contaminante atingir a água subterrânea.

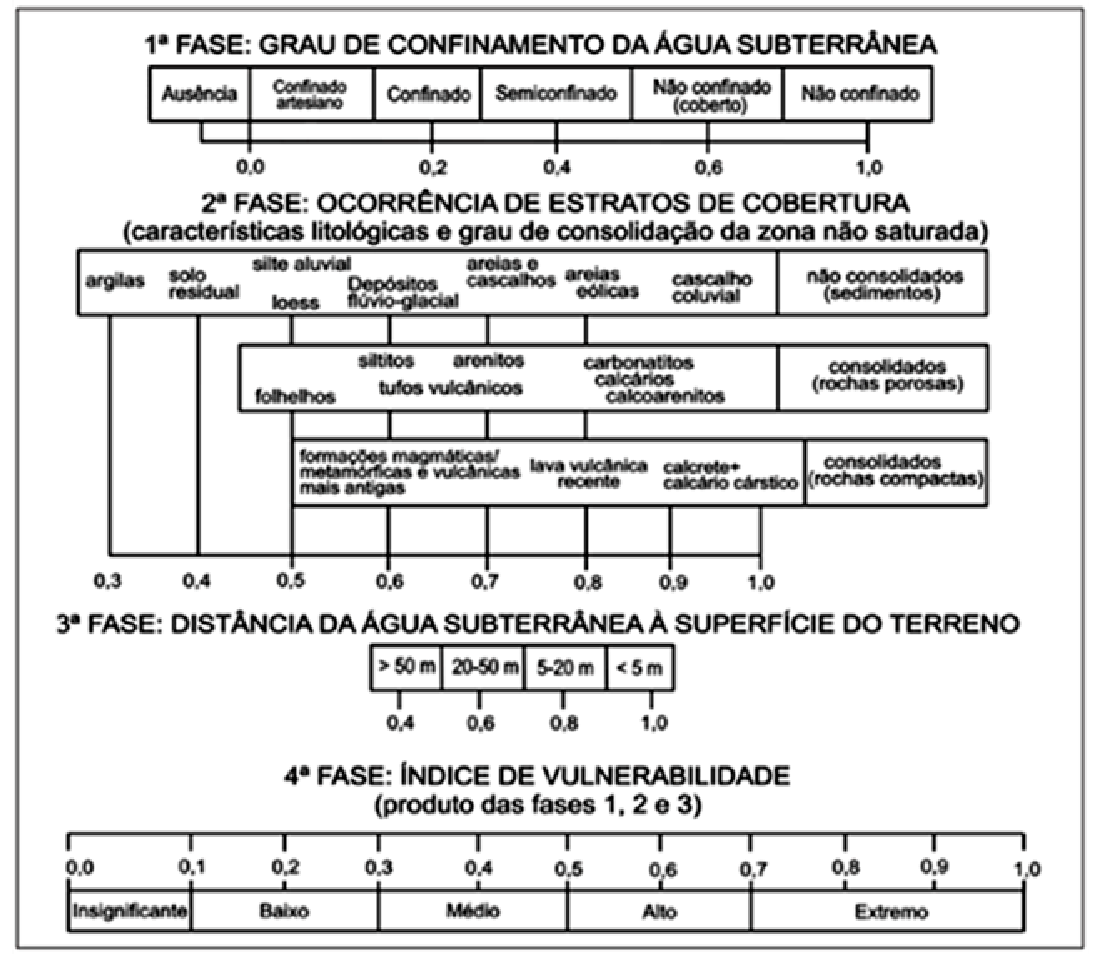

Figura 2. Sistema $G O D$ para avaliação da vulnerabilidade do aquífero à contaminação. Fonte: Foster et al. (2006).

Ao ocorrer mais de um estrato litológico no perfil de determinada captação, calculou-se o percentual relativo a cada formação e estimou-se seu valor no intervalo.

Após a pontuação das três etapas é feito o produto dos valores obtendo-se a(s) classe(s) de vulnerabilidade da qual pertence as águas. Este índice de vulnerabilidade pode ser considerado: Desprezível (0 a 0,1), Baixa $(0,1$ a 0,3), Média $(0,3$ a 0,5), Alta $(0,5$ a 0,7) e Extrema $(0,7$ a 1,0) (Figura. 2).

Com a utilização dos programas ArcGIS 9.2, Surfer 8.0 e com as coordenadas dos poços (sistemas de coordenadas UTM/SAD69 e Datum vertical com referência no Porto de Ibitúba SC), obteve-se os resultados espacializados em forma de cartogramas. Assim, tornando possível a visualização das áreas de maior e menor risco à contaminação e também mostrando a tendência de direção do fluxo subterrâneo da água através da superfície potenciométrica. Heath (1983) considera superfície potenciométrica como sendo a linha em mapa ou em corte vertical ao longo da qual as cargas totais são as mesmas. Obtem-se esta relação entre a cota altimétrica na "boca" do poço até o nível da água. Ela representa uma carga hidráulica sobre um "datum" de referência. Com uso do programa Surfer 8.0 utilizou-se os interpoladores matemáticos indicativos das tendências dos fluxos, sendo estes são traçados perpendicularmente as linhas equipotenciais. Selecionou-se o interpolador krigagem nessa pesquisa. 


\section{RESULTADOS PRELIMINARES}

Observando-se o cartograma (Figura. 3) de índice de vulnerabilidade do aquífero à contaminação, nota-se que a classe predominante na área do estudo (ZA) do SAG foi a Alta (com 40,00\%), seguida de vulnerabilidade Média (com 28,57\%), Baixa (14,29\%), Extrema (14,29\%) e Insignificante (2,85\%).

Os principais pontos potenciais de contaminação avaliados foram: Postos de combustíveis e cemitérios, estão localizados na área urbana ou de expansão urbana, onde foi construída a Estação de Tratamento de Esgotos. Esta recebe uma parcela dos esgotos do município. À jusante do Rio Santa Maria.

O curso principal do Rio Santa Maria, onde é praticado o cultivo de arroz irrigado no período de verão (Novembro-Março) tem-se o uso de Agrotóxicos, inseriu-se na classe Média de vulnerabilidade. Já no encontro com o Rio Ibicuí da Armada, onde recebe parte dos esgotos "in natura" encontra-se na classe Alta, passando a Extrema. Evidenciando vulnerabilidade.

Já o Rio Ibicuí da Armada onde também ocorre cultivo de arroz dá-se então, nas classes Alta e Média vulnerabilidades como apresentado na figura 3.

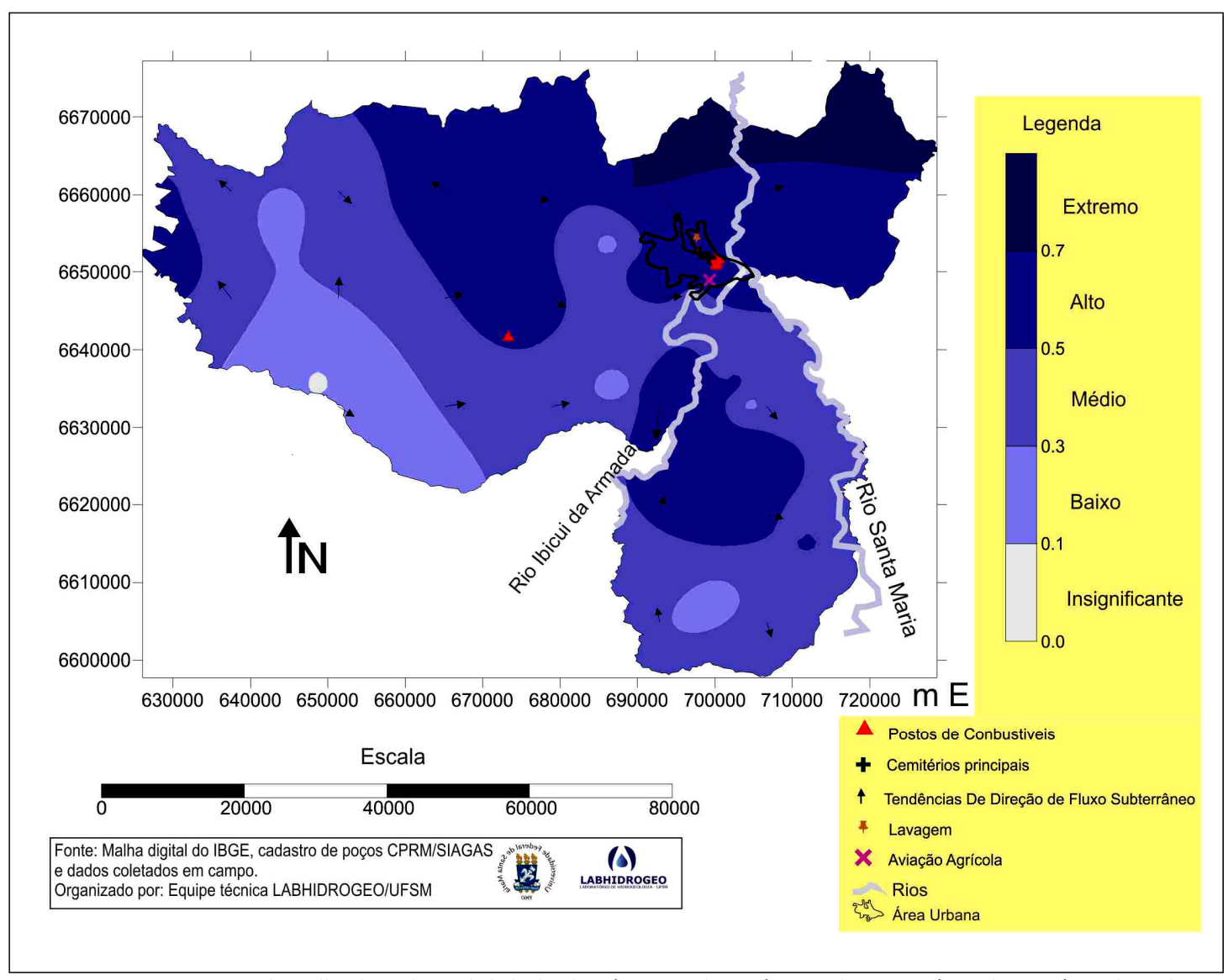

Figura 3. Espacialização da vulnerabilidade das águas subterrâneas do município de Rosário do Sul RS.

O estudo de direção de fluxo das águas subterrâneas, como é visto na Figura 4, é importante para se obter a tendência de direção e o sentido da pluma em caso de contaminação subterrânea. Como existe grande circulação de água subterrânea, conhecendo-se o seu 
direcionamento, pode-se planejar ações voltadas a minimizar os riscos ou evitar a instalação de empreendimentos poluidores na (ZA) do SAG.

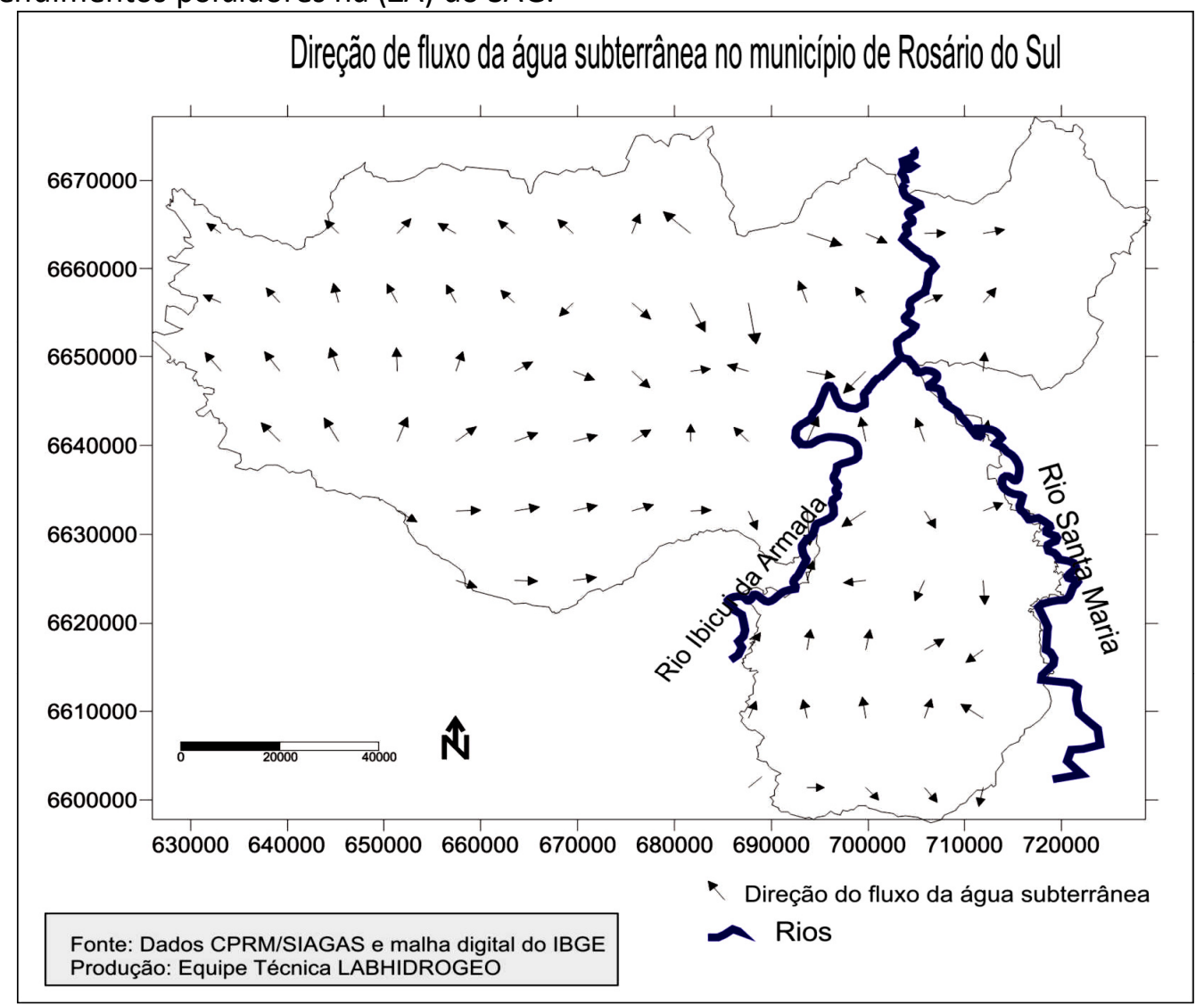

Figura 4. Tendência de direção de fluxo das águas subterrâneas do município de Rosário do Sul RS.

Observou-se as tendências indicativas pelas direções dos vetores de contribuição do aquífero na perenização dos cursos de água (Rio Santa Maria e Rio Ibicuí da Armada). Condição de rio efluente recebendo água proveniente das rochas sedimentares arenosas, que compõem o aquífero livre pertencente ao (SAG). Devido à presença de sete postos de combustíveis e cemitérios na área urbana de Rosário do Sul (área de alto risco à contaminação), existem riscos potenciais de contaminação a serem monitorados.

Considerou-se as tendências dos fluxos subterrâneos em sentido aos cursos de água, devem ser considerados os possíveis riscos de contaminação nos rios. A FEPAM realiza trimestralmente o monitoramento da água superficial, más a qualidade físico-química das águas subterrâneas ainda não são monitoradas. Este monitoramento deverá ser executado pela CPRM/RIMAS em poço tubular instalado na ETA da CORSAN

\section{CONSIDERAÇÕES FINAIS}

Através do cadastro de poços pode-se observar na aplicação do método GOD que na (ZA) do SAG em Rosário do Sul ocorrem classes de vulnerabilidade predominantes entre Baixa, Média e Alta, as quais devem ser consideradas nos planos de ocupação do uso do solo, na área urbana e/ou de expansão. 
Sugere-se executar estudos físico-químicos e bacteriológicos para avaliação das classes de enquadramento do aquífero na zona urbana.

A execução do método GOD é relativamente fácil quando comparada a outros métodos de avaliação de vulnerabilidade de aquíferos. Estes estudos buscaram a interação rio-aquífero. E servem como subsidio a órgãos gestores como os comitês de bacias hidrográficas.

\section{REFERÊNCIAS}

BRASIL/CNRH - Conselho Nacional de Recursos Hídricos - Resolução №15, 11 de janeiro de 2001 http://www.cnrh.gov.br/sitio/index.php?option=com_content\&view=article\&id=14 acessado em 20 de maio de 2012

BRASIL/CPRM/SIAGAS Sistema de Informações de Águas Subterrâneas - Banco de dados dos poços cadastrados em Rosário do Sul, disponível em <http://siagasweb.cprm.gov.br/layout/pesquisa_complexa.php> acesso em 25 de abril de 2012. BRASIL/MMA/CONAMA - Conselho Nacional de Meio Ambiente - controle da poluição em postos de combustíveis, disponível em http://www.mma.gov.br/port/conama/legiabre.cfm?codlegi=271 acesso em 20 de abril de 2012.

BRASIL - Projedo de rede integrada de monitoramento das águas subterrâneas - RIMAS.

Disponível em <www.cprm.gov.br> acesso em 5 jun. 2012

BRASIL/MMA/CONAMA - Conselho Nacional de Meio Ambiente - licenciamento ambiental de cemitérios, disponível em <http://www.mma.gov.br/port/conama/legiabre.cfm?codlegi=359> acesso em 25 de abril de 2012.

BRASIL/SEMAS/CAGE Secretaria do Meio Ambiente - DECRETO N 42.047, DE 26 DE DEZEMBRO DE 2002

<http://www.legislacao.sefaz.rs.gov.br/Site/Document.aspx?inpKey=106552\&inpCodDispositive= \&inpDsKeywords=10350> Acesso em 16 de maio de 2012.

BRASIL/SENADO/LEGISLAÇÃO. Leis constitucionais -

Art.24<http://www.senado.gov.br/legislacao/const/con1988/CON1988_05.10.1988/CON1988.pdf

. Acesso em 16 de maio de 2012.

BRASIL - Portaria ministério da saúde $n^{\circ} 2914 / 11$ de dezembro 2011. Disponível em <http://www.brasilsus.com.br/legislaçoes/gm/110982-2914.html> acesso dia 5 jun. 2012.

DESCOVI FILHO, L. L. V.; Subsídios ambientais para a gestão das águas subterrâneas na Bacia

Hidrográfica do Rio Santa Maria-RS. Dissertação (Mestrado do Programa de Pós Graduação em Engenharia Civil - Recursos Hídricos e Saneamento Ambiental) - Centro de Tecnologia, UFSM. 2009.

ESRI. Environmental Systems Research Institute (2006) ArcGIS Professional GIS for the desktop, version 9.2. Software. Licensed to UFSM, 2008.

FOSTER, S; HIRATA, R; GOMES, D; D'ELIA, M; PARIS, M. Proteção da Qualidade da Água

Subterrânea: um guia para empresas de abastecimento de água, órgãos municipais e agências ambientais. São Paulo, Servemar. 2006.

GUIGUER, N. Poluição das Águas subterrâneas e do Solo Causada por Vazamentos em Postos de Abastecimento. Santo André SP, waterloo hydrogeologic. 2000.

HEATH, R. C. Hidrologia Básica de Água Subterrânea. USGS Water Supply Paper 2220. Traduzido para o Português Mario Wrege e Paul Potter. UFRGS/IPH, 1983. p.84. 
Organization of American States (OAS) (2009) Guarani Aquifer: Strategic Action Program/SAP = Acuífero Guaraní: Programa Estratégico de Acción/PEA - Bilingual edition- Brazil, Argentina, Paraguay, Uruguay, January, 2009, 224p.

PAVÃO, A. D. M. Avaliação do Índice de Vulnerabilidade na Bacia Hidrográfica do Rio Santa Maria - RS.. Dissertação de Mestrado do Programa de Pós-Graduação em Engenharia Civil. Universidade Federal de Santa Maria. 2004.

RIBEIRO L. Desenvolvimento e aplicação de um novo índice de susceptibilidade dos aquíferos à contaminação de origem agrícola - in Actas do 70 Simpósio de Hidráulica e Recursos Hídricos dos Países de Língua Oficial Portuguesa, ed. CDROM, APRH, Évora, Portugal. 2005, p.14.

Siagas [sistema de informações de águas subterrâneas], (2009) Companhia de Pesquisa e Recursos Minerais, CPRM, Disponível em:

<http://siagas,cprm,gov,br/wellshow/indice,asp?w=1024\&h=764\&info=1> Acesso em: 27 Abril 2009,

SILVA, R. C. A.; ARAUJO, T. M. Qualidade da água do manancial subterrâneo em áreas urbanas de Feira de Santana (BA). Ciência \& Saúde Coletiva, v. 8 n. 4, p. 1019-1028. 2003.

SILVÉRIO DA SILVA, J. L.; DAMBRÓS, C. Recraga e flutuação do nível da água subterrânea em subbacias com floresta e campo nativo. XI Congresso Latinoamericano de Hidrogeologia. 2012.

SILVÉRIO DA SILVA, J. L.; DAMBRÓS, C.; DESCOVI FILHO, L. L. V. Mapeamento da vulnerabilidade do aquífero à contaminação no Município de Rosário do Sul - RS, Brasil. XV Simpósio Brasileiro de Sensoriamento Remoto. 2011.

Surfer 8 (2002) Contouring and 3D Surface Mapping for Scientists and Engineers. User's Guide Goldensoftware. 640p. 